\title{
An Android Based Automated Tool for Performance Evaluation of a Course Teacher (CTE)
}

\author{
Mahfida Amjad \\ Stamford University Bangladesh, Dhaka, Bangladesh \\ Email: mahfidaamjad@gmail.com \\ Hafsa Akter \\ Stamford University Bangladesh, Dhaka, Bangladesh \\ Email: hafsahaque656@gmail.com
}

Received: 20 March 2020; Accepted: 04 May 2020; Published: 08 October 2020

\begin{abstract}
For the betterment of teaching methodology student's evaluation is an integral part of any educational organization. To achieve this process the authority needs to know how the teachers are teaching and therefore the interaction between the learners and therefore educators. This paper develops an android based automated tool for performance evaluation of a course teacher (CTE) which is able to create an educator's performance report from the student's evaluation based on some predefined questionnaire by using an android mobile device with internet connectivity from anywhere and anytime. The performance report is auto generated together with a graph and it also creates a file to send the teacher if the authority wants to inform the educator. With the assistance of this technique, course teachers can easily understand their current situation of their corresponding courses where they should focus on.
\end{abstract}

Index Terms: Performance evaluation, automated tool, educator's performance, android application, mobile device.

\section{Introduction}

Assessment refers to a quantitative appraisal of the faculty planned for distinguishing its qualities, shortcoming, and giving sufficient expert advancement openings. It includes the utilization of classroom perceptions, understudy assessment reports, and so forth. to quantify the exhibition and viability of an instructor. The goal is to give instructive input to help the teachers in improving the adequacy of their educating performance. It manages the expert advancement of personnel, improvement other than classroom education.

Nowadays Higher Educational Institutions (HEIs) are confronting the challenge of improving the quality of scholastics. Understudy fulfillment reviews are ordinarily utilized as an apparatus to catch the nature of instructing and learning. They can without a doubt give significant data to the senior administration of HEIs giving bits of knowledge on their qualities and shortcomings [1].

Taking criticism of instructors from understudies in a class is a significant movement of any instructive establishment. Traditionally educators' criticism assessment framework is a survey based framework were a pre-planned A poll structure is given to every student. The structure may have at least 10 questions and students relegate an evaluation to each address for each instructor as per the predefined estimating scale. Based on reactions, all things considered, it is resolved how much an educator can contribute to his/her course. The main trouble of questionnaire based system is that it is totally manual and takes too much time to give a result. It also needs an authenticated and trusted person to carry on the evaluation.

Right now we live in a time where the internet has carried numerous advantages to people, associations, and organizations. With the fast improvement of data innovation in the world, we attempt to make our life simpler through information technology. And now-a-days, most of the individuals use electronic gadgets like mobile, tab, and so forth. And for this reason, this paper also tries to utilize the information technology to make educator's evaluation faster, accurate, and automated through the help of internet and the android mobile device. This research develops an android based automated tool for performance evaluation of a course teacher (CTE) which is the extended version of web based automated tool (TTE) for course teacher evaluation system [13]. This tool is designed for Stamford University Bangladesh to measure the effectiveness of the teaching procedure of a faculty. CTE uses a predefined questionnaire which is evaluated by the students. They can use this application anytime from anywhere to evaluate the teacher 
through a mobile device that has internet access. After completing the evaluation the moderator of the application can view the auto generated graph which is based on the evaluation result along with a pdf file for further use.

This research will try to find out the following questions-

1) How much it is feasible to make the teacher's evaluation automated?

2) Is the performance evaluation of the educators can be done by the students anytime from anywhere?

3) Is the performance evaluation can be done without any trusted party?

4) Is it possible to make the analysis of the evaluation within a few seconds?

5) How much the system is secured?

Therefore, the objectives of this research are as follows-

1) To make an automated tool for performance evaluation of a course teacher which will be platform independent?

2) With the help of the wireless technology and internet facility this automated tool can be accessible from anywhere in anytime.

3) As the tool will be automated there will be no need of any manpower to analysis the evaluated data.

4) The analysis of the performance evaluation can be done in just a click as it will be designed through android mobile application.

5) The authority needs not to worry about the privacy or security as all the data will be stored in the cloud.

The rest of this paper is organized as follows. Section II describes the literature review, Section III illustrated the system design and implementation and Section IV is about discussion and future work. This paper will be ended in Section V.

\section{Literature Review}

This section contains the brief discussion of some existing works related to teacher evaluation system.

In the paper [2] it offers proof that assessment can move the instructor viability dispersion through an alternate component: by improving educator ability, exertion, or both in manners that continue since quite a while ago run. It studies an example of mid-profession math educators in the Cincinnati Public Schools (CPS) who were allocated to assessment in a way that allows a semi trial investigation. All educators in this example were assessed by a year-long classroom perception based program, the treatment, between 2003-2004 and 2009-2010; the planning of every instructor's particular assessment year was resolved years earlier by a district planning process. It finds that instructors are progressively beneficial during the school year when they are being assessed, however much increasingly profitable in the years after assessment.

The writing [3] features the head as key to educator assessment. Great instructor assessment includes numerous information sources, for example, teacher's overviews, peer surveys, and student accomplishment information, which differ by educator and setting. Authorities ought to get educated about student gain information, expenses of assessment, human science of instructor assessment, and the issue of the low performance educators. Teacher evaluation can reassure external audiences that administrations are doing a good job.

The impacts of classroom practices, when added to those of other educator qualities, are practically identical in size to those of student foundation, proposing that instructors can contribute as a lot to student learning as the students themselves [4].

The paper [5] includes both classroom observations and student accomplishment growth measures. It provides feedback to teachers for improvement which is aligned to professional development and mentoring support, and provides metrics for performance-based compensation.

Advancements like Artificial Intelligence had an amazing development in numerous fields particularly in instructive educating and learning forms. Advanced education organizations have begun to embrace the utilization of innovation into their conventional showing components for upgrading learning and instructing. There are several research works like $[1,6,10,11,12]$ which uses machine learning algorithms to predict, classify, and analyze student reviews for faculty evaluation.

The paper [13] has presented a web based automated tool for Course Teacher Evaluation System (TTE). In this technique student's opinions are taken from predefined 10 questions in a web based platform for evaluating a teacher of any particular course. The result from the data analysis is automatically generated along with a graphical representation. From the generated report it becomes easy for the course teacher to understand and focus on the area where they need to emphasize for their personal and professional growth. 


\section{Application Design and Execution}

In this section this paper will describe how the CTE application works showing all the interfaces. There are two parts of CTE, one for admin or the moderator and another for student. Here the basic interfaces are shown step by step with the block diagrams.

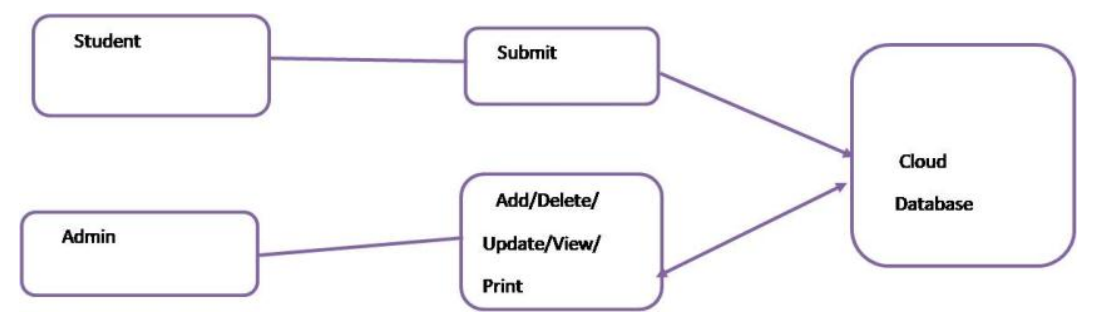

Fig. 1.Block diagram of CTE

Fig. 1 shows the block diagram of the CTE app. The first interface of this app has been shown in Fig. 2 which contains two options for selecting the user.

\section{A. Interface Design}

The interfaces of CTE are divided into two parts, one is for admin and another is for student. The student interfaces are Sign Up, Sign In and Evaluation Form. And the admin interfaces are Sign Up, Teachers, Teacher Details, Add Teacher, Batches, Batch Details, Add Batch, Course, Course Details, Add Course, Select Teacher Information and Result Mark Sheet etc.

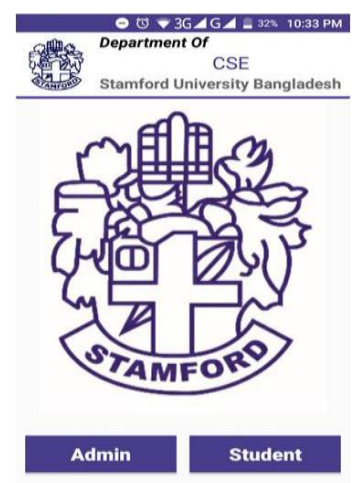

Fig. 2. Screenshot of Admin or Student Choice Interface

\section{1) Design of Student Interface}

In the CTE app the students have to register for doing teacher evaluation. Fig. 3 shows the sign up option for the student. After registration, student will be able to sign in. Students have to register themselves by giving their student ID. After registration they will be able to sign in. For evaluating they have to select Batch which have to be matched with their student ID (every student ID includes batch name), so that student of one batch can not evaluate another batch's teacher. As well as, like Fig. 4 students have to select batch section, course code, course title and course teacher. All fields must be selected to get access to the evaluation form like Fig. 5. 


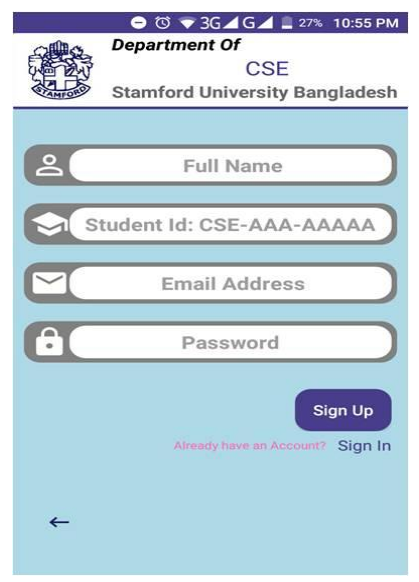

Fig. 3. Screenshot of Student Signup

Fig. 4. Screenshot of Student Home Page

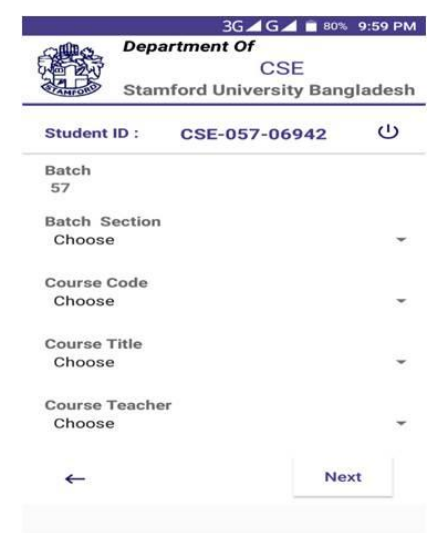

Hig. 4. Screenshot of Stident Home Page
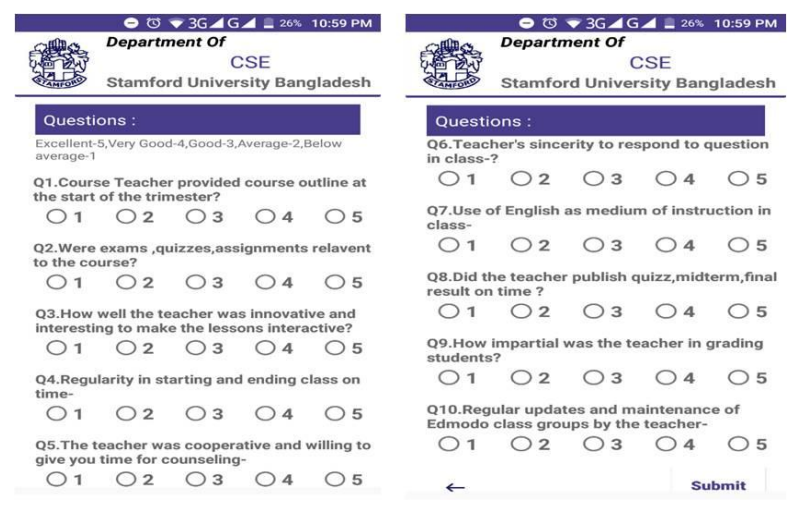

Fig. 5. Screenshot of Evaluation Form

\section{2)}

Design of Admin Interface

Admin also has to register for using this CTE app. There is sign up option for registration. After registration admin will be able to Sign in like Fig. 6. Admin has to register them using their email id. After signing in at the home page of the admin interface, there are three options $\leftarrow$ (back), Dashboard and Next like Fig. 7. Back sign will let the Admin to go back to the main page of the app. By Clicking Dashboard button it will let the Admin to go where Admin can view teacher, batch and course list. By clicking Next button Admin will be able to see the evaluation result of the educator choosing batch wise course list with educator's name. In Fig. 8 and 9 it shows the evaluation result with graph. Admin can also create a pdf file of the result which can be store in the phone storage. 
Fig. 6. Screenshot of Admin Sign in
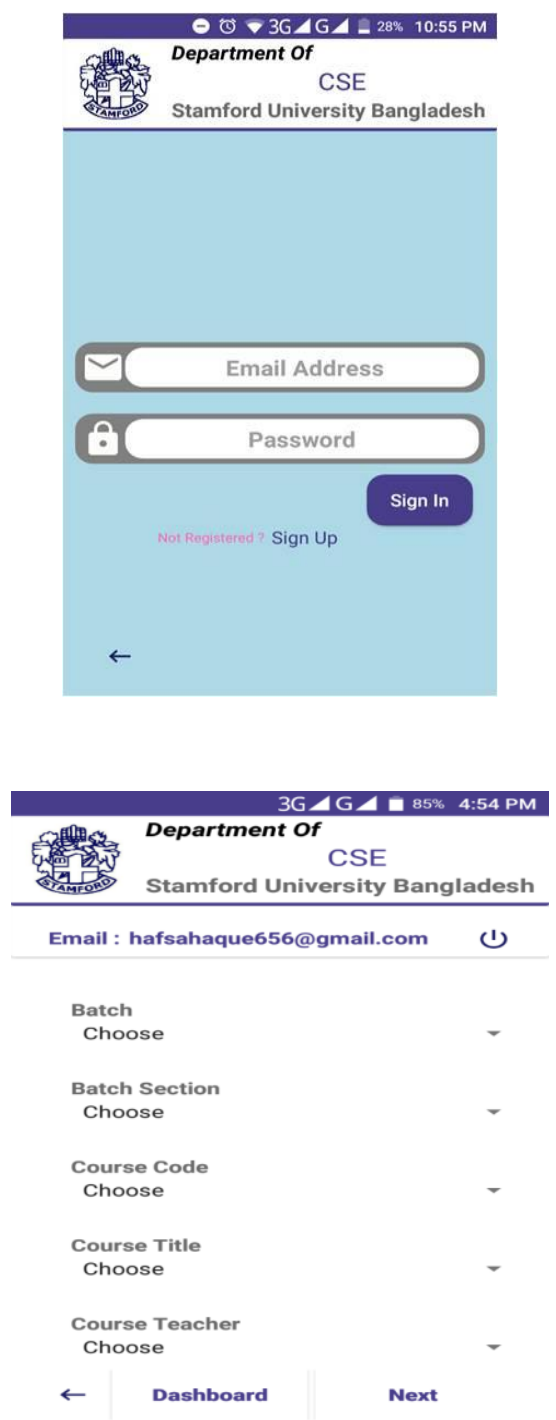

Fig. 7.Screenshot of Home Page

Fig.8. Screenshot of Evaluation

\begin{tabular}{|c|c|c|c|}
\hline 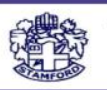 & \multicolumn{3}{|c|}{$\begin{array}{c}\text { Department of } \\
\text { CSE } \\
\text { Stamford University Bangladesh }\end{array}$} \\
\hline \multicolumn{4}{|c|}{ Welcome to Teacher Evaluation Result } \\
\hline Title & \\
\hline $\begin{array}{l}\text { Code } \\
\text { Teacher }\end{array}$ & \multicolumn{3}{|c|}{$\begin{array}{l}\text { : CSI } 413 \\
\text { : Mahfida Amjad Dipa }\end{array}$} \\
\hline $\begin{array}{l}\text { Batch } \\
\text { Questions }\end{array}$ & $: 57$ & Section : & \\
\hline \multicolumn{3}{|c|}{$\begin{array}{l}\text { Q1. Course Teacher provided course } \\
\text { outline at the start of the trimester? }\end{array}$} & 4.5 \\
\hline \multicolumn{3}{|c|}{$\begin{array}{l}\text { Q2. Were exams, quizzes,assignments } \\
\text { relavent to the course? }\end{array}$} & 3 \\
\hline \multicolumn{3}{|c|}{$\begin{array}{l}\text { Q3. How well the teacher was } \\
\text { innovative and interesting to make the } \\
\text { lessons interactive? }\end{array}$} & 3.5 \\
\hline \multicolumn{3}{|c|}{$\begin{array}{l}\text { Q4.Regularity in starting and ending } \\
\text { class on time- }\end{array}$} & 1.5 \\
\hline \multicolumn{3}{|c|}{$\begin{array}{l}\text { Q5. The teacher was cooperative and } \\
\text { willing to give you time for counseling- }\end{array}$} & 4 \\
\hline \multicolumn{3}{|c|}{$\begin{array}{l}\text { Q6. Teacher's sincerity to respond to } \\
\text { question in class-? }\end{array}$} & 4 \\
\hline \multicolumn{3}{|l|}{ Q7.Use of } & \\
\hline
\end{tabular}




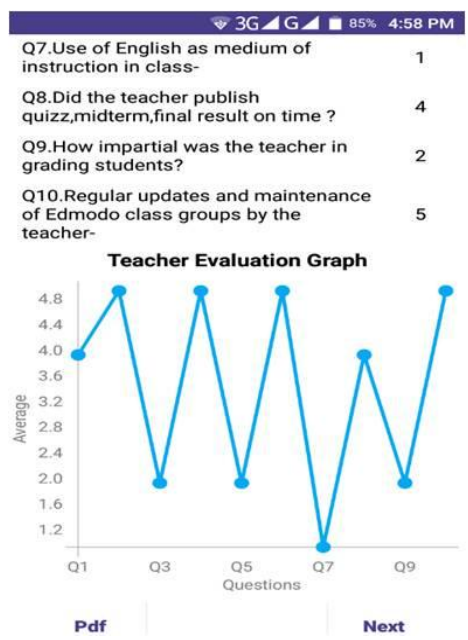

Fig.9. Screenshot of Evaluation Graph

B. Execution

The CTE application is executed by two types of user, one is Admin and another is Student. The execution of CTE app can be explained like the following algorithms and activity diagrams.

1) Algorithm and Flowchart of Student Panel

For evaluating a faculty the student has to perform the following steps one by one like algorithm 1 . And Fig. 10 shows the flowchart of Algorithm 1 for student panel.

\section{Algorithm 1. Steps of the Student Panel}

State: Student

Sign Up: Full Name, Student ID, Email Address, Password

Sign In: Email Address, Password

Home Page: Batch, Batch Section, Course Code, Course Title, Course Teacher

Evaluation Form: 10 Questions

Sign Out:

Step 1: [Start]

Step 2: [Selection]

Student or Admin

Step 3: [Sign Up/Sign In]

Give proper inputs

Step 4: [Home Page]

Select all the fields for getting access to the evaluation form

Step 5: [Evaluation Form]

Evaluate the 10 questions

Step 6: [Sign Out]

Sign Out from the app

Step 7: [End] 


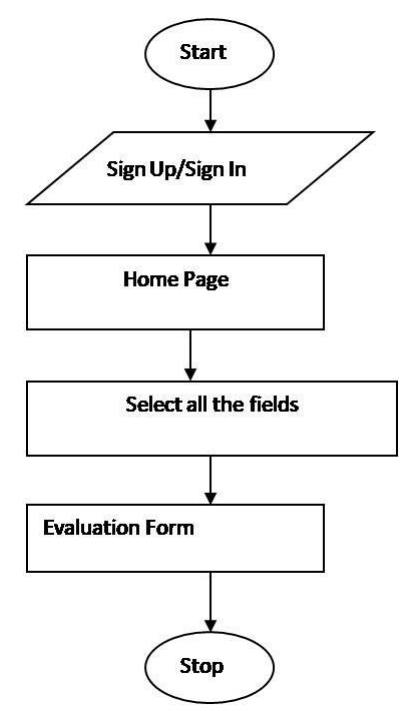

Fig. 10. Flowchart of Student Panel

\section{2) Algorithm and Flowchart of Admin Panel}

For viewing the result of the evaluation of an educator the admin has to perform the following steps one by one like Algorithm 2. Fig. 11 shows the flowchart of Algorithm 2 for admin panel.

\section{Algorithm 2. Steps of the Admin Panel}

State: Admin

Sign Up: Full Name, Student ID, Email Address, Password

Sign In: Email Address, Password

Home Page: Batch, Batch Section, Course Code, Course Title, Course Teacher

Go Back: Home Page

Dashboard: Add/Delete/ Update Course, Batch, Faculty

Next: Evaluation Result

Sign Out:

Step 1: [Start]

Step 2: [Selection]

Student or Admin

Step 3: [Sign Up/Sign In]

Give proper inputs

Step 4: [Home Page]

Select all the fields for getting access to view the evaluation result by clicking Next button result

By clicking pdf in the result graph interface the admin can create, print or save the pdf version of the evaluation

By clicking Dashboard button the Admin can Add/Delete/Update/View the Course List, Faculty List, Batch List

Step 5: [Sign Out]

Sign Out from the app

Step 6: [End] 


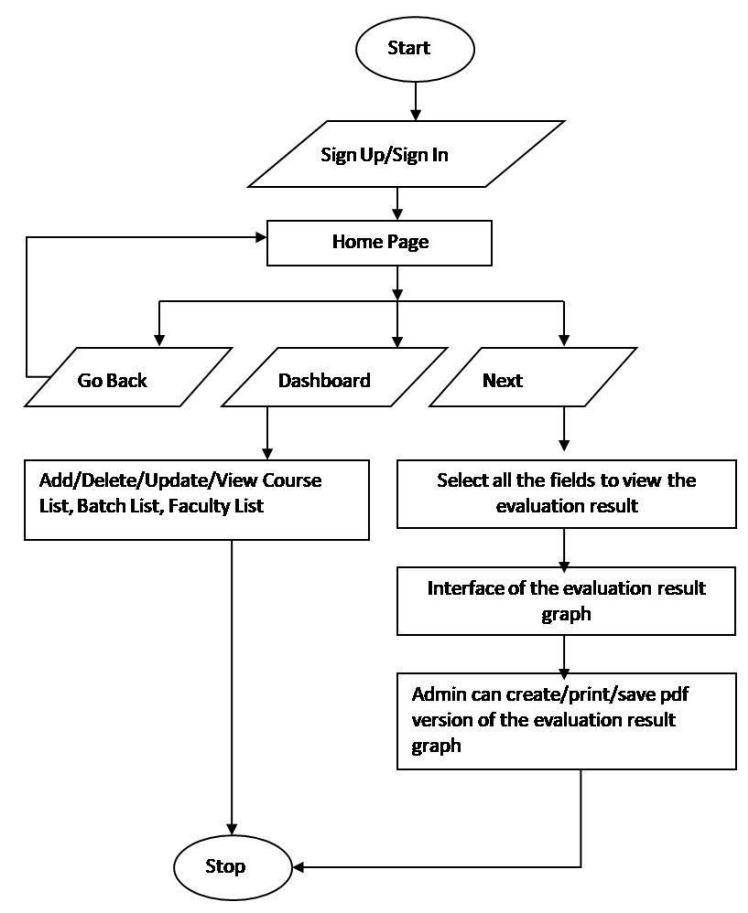

Fig. 11. Flowchart of Algorithm 2 of Admin Panel

\section{System Requirements and Technical Specification}

For developing this CTE tool technology like Android Studio, Firebase Real Time Database and Authentication has been used. This section will give a brief about these technologies.

\section{A. Android Studio}

Android Studio is the official Integrated Development Environment (IDE) for Android Application development. It is based on the IntelliJ IDEA, a Java integrated development environment for software, and incorporates its code editing and developer tools. On top of the capabilities one expects from IntelliJ, Android Studio Offers:

1) Build variants and multiple apk file generation

2) Code templates to build common app features

3) Rich layout editor with support for drag and drop theme editing

4) Tools to catch performance, usability, version compatibility, and other problems

5) ProGear and app-signing capabilities

6) Built in support for Google Cloud Platform, making it easy to integrate Google Cloud Messaging and App Engine and much more [6].

\section{B. FireBase Realtime Database and Authentication}

All the data of CTE are stored and synchronized with NoSQL cloud database. Data is synced across all clients in realtime and remains available when app goes offline. The Firebase Real Time database is a cloud hosted database. Data is stored as JSON and synchronized in real time to every connected client. When one builds cross platform apps with iOS, Android, and JavaScript SDKs, all clients share one Real time Database instance and automatically receive updates with the newest data [8].

Most apps need to know the identity of a user. Knowing a user's identity allows an app to securely save user data in the cloud and provide the same personalized experience across all of the user's devices. Firebase Authentication provides backend services, easy-to-use SDKs, and ready-made UI libraries to authenticate users to the app. It supports authentication using passwords, phone numbers, popular federated identity providers like Google, Facebook and Twitter, and more [9].

\section{Discussion and Future Work}

This section discusses the advantages of the CTE application and also indicates the limitations. This section will also give a direction to future scope of work. 
A. Advantages of CTE

1) It takes very little time to complete the evaluation procedure.

2) The result is auto-generated with a graph.

3) The result can be saved in form of pdf file.

4) It does not need any human resource for calculating the evaluation result.

5) From this application the authority can find out the situations of the faculties.

6) This application is executable from any android based mobile device.

\section{B. Limitations}

In this CTE application the Admin is unable to notify the faculty of their evaluation result of corresponding courses by sending the pdf file. And there is also no panel for the faculty to view their current situation of their courses.

\section{Future Work}

In future this application will be developed to solve these limitations to make it more effective and fruitful. This system has been made for only the department of Computer Science and Engineering of Stamford University Bangladesh. Near future it will also make a generalized version for any departments of any organizations for faculty evaluation to serve better education system.

\section{Conclusion}

There is no doubt that the performance evaluation of educators in any educational organization is very much important for the betterment of the education system. Student's evaluation of their educators can change the learning environment. By doing this it also helps the teachers to realize the situation of their particular courses. Considering this fact this research develops an android based automated tool for performance evaluation of educators (CTE). CTE enables the institution to view the performance evaluation of their faculties to find out their current academic situation along with an automated graph that is generated from the student's reviews through any mobile device with internet connectivity. It saves the computation time and also the needs of trusted manpower for carrying this evaluation process. And it is also secured as it uses the cloud server for storing the data. In the future, this research will try to make it more customizable, user friendly, and generic for any kind of educational institution for the purpose of performance evaluation.

\section{Acknowledgment}

The authors wish to thank all the faculties of CSE department of Stamford University Bangladesh. This work is supported in part by CSE department of Stamford University Bangladesh.

\section{References}

[1] Suman Bhatnagar, Prof. Prashant Sahai Saxena, "Analysis of Faculty Performance Evaluation Using Classification", International Journal of Advanced Research in Computer Science, Volume 9, No. 1, 2018.

[2] Eric S Taylor \& John H Tylor, "The Effect of Evaluation on Teacher Performance", American Economic Review, 2012.

[3] Peterson, Kenneth. (2004). Research on School Teacher Evaluation. Nassp Bulletin. 88. 60-79. 10.1177/019263650408863906.

[4] Wenglinsky, H., "How schools matter: The link between teacher classroom practices and student academic performance" Education Policy Analysis Archives, 2012.

[5] Daley, Glenn A. and Lydia Kim, "A Teacher Evaluation System That Works" The National Institute for Excellence in Teaching (NIET), 2010

[6] Boran Sekeroglu, Kamil Dimililer, Kubra Tuncal, "Student Performance Prediction and Classification Using Machine Learning Algorithms", 8th International Conference on Educational and Information Technology, Pages 7-11, March 2019, https://doi.org/10.1145/3318396.3318419.

[7] En.wikipedia.org, Android Studio. [online] Available at: https://en.wikipedia.org/wiki/Android_Studio.

[8] Firebase.google.com, Firebase Realtime Database. [online] Available at: https://firebase.google.com/docs/database

[9] Firebase.google.com, Firebase Authentication. [online] Available at: https://firebase.google.com/docs/auth.

[10] Noman Islam, “A Three-Pronged AI Solution for Faculty Evaluation”, Presented at International Conference on Innovation and Emerging Trends in Business Management, Education and Social Sciences, 9-10 January, 2018.

[11] G. Gutiérrez, J. Ponce, A. Ochoa, M. Álvarez, "Analyzing Students Reviews of Teacher Performance Using Support Vector Machines by a Proposed Model”, International Symposium on Intelligent Computing Systems (ISICS), pp 113-122, 2018.

[12] Alok Kumara, Renu Jainb, "Faculty Evaluation System", 6th International Conference on Smart Computing and Communications (ICSCC), December 2017.

[13] Mahfida Amjad, Nusrat Jahan Linda, "A Web Based Automated Tool for Course Teacher Evaluation System (TTE)", International Journal of Education and Management Engineering 10(2):11-19, DOI: 10.5815/ijeme, April 2020. 


\section{Authors' Profiles}

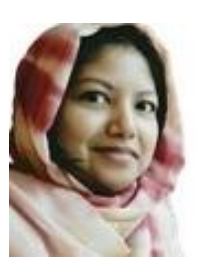

Mahfida Amjad was born in 1985 in Dhaka, Bangladesh. She has completed her Master degree in Information Technology from Institute of Information Technology from University of Dhaka in 2009. And she completed B.Sc. in Computer Science \& Engineering from Manarat International University in 2007. She is a faculty member of Computer Science and Engineering (CSE) Department of Stamford University Bangladesh. She has devoted herself in teaching profession since 2012. Her research area is wireless communication network and software engineering.

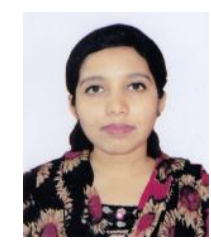

Hafsa Akter was born in 1996 in Bangladesh. She has completed B.Sc in Computer Science and Engineering from Stamford University Bangladesh in 2019. Currently she is working on Android Mobile Application Development .

How to cite this paper: Mahfida Amjad, Hafsa Akter, " An Android Based Automated Tool for Performance Evaluation of a Course Teacher (CTE)", International Journal of Information Engineering and Electronic Business(IJIEEB), Vol.12, No.5, pp. 14-23, 2020. DOI: $10.5815 /$ ijieeb.2020.05.02 